\title{
Are patterns of flower differentiation in response to nutrient supply and pollen concentration optimal for fruit and seed growth?
}

Lei Gao ( $\sim$ gaolei@m.scnu.edu.cn )

South China Normal University https://orcid.org/0000-0001-5708-029X

Jun Jie Zhai

South China Normal University

Guo Zhu Yu

South China Normal University

Wei Hua Li

South China Normal University

Chang Lian Peng

South China Normal University

Research article

Keywords: Cucumber, Plant fitness, Sex differentiation, Monoecious, Pollen resource

Posted Date: September 8th, 2019

DOI: https://doi.org/10.21203/rs.2.14097/v1

License: (a) This work is licensed under a Creative Commons Attribution 4.0 International License.

Read Full License 


\section{Abstract}

Background Changes in the proportions of male and female flowers in monoecious plants in response to external environmental conditions are directly related to the reproductive fitness of plants. The monoecious cucumber plant was used in this study to assess the responses of sex differentiation and the breeding process to nutrient supply and the degree of artificial pollination using pollen solutions of different concentrations.

Results We found that the nutrient supply significantly increased the number of female flowers after pollination, although the number of female flowers did not increase with the concentration of the pollination solution. The number of male flowers did not decrease even under the low nutrient concentration; consequently, the optimal benefits under different nutrient and pollen resources in the environment were maximized when the number of female flowers decreased due to low nutrient levels after pollination. Pollination treatment affected the fruit growth, seed set, and fruit yield. However, the number of fruit, fruit set percentage, and total seeds per plant did not increase with the pollination level, although the fruit weight and seed number in one fruit did increase. The trade-offs for cucumbers associated with flower differentiation with respect to nutrient supply and pollination may not be optimal for fruit growth or seed set.

Conclusions It is concluded that the response of plant flowering to external factors is direct and instantaneous, and there may not be an overall and long-term resource allocation for fruit development and seed formation.

\section{Background}

Responses of the plant reproductive system to external resources and the environment are central to the study of plant evolution [1]. Plant fitness is an important means of evaluating plant responses to environmental factors [2,3]. Plant fitness serves as an index for evaluating the adaptability of plant characteristics in specific environments and the contribution of individual plants to producing the next generation [4]. To achieve optimal fitness, plants have many trade-off strategies in resource acquisition and distribution. For example, there is a trade-off between roots and leaves in acquiring resources, such as water, soil nutrients, and sunlight $[5,6]$. There are also trade-offs in reproductive allocation between flowers, fruits, and seeds for the optimal fitness of offspring $[7,8]$.

To determine the optimal fitness of genetic resources in offspring, plants have evolved many strategies, such as dichogamy, herkogamy, and monoecy $[9,10]$. Many plants have a self-incompatibility strategy that increases the genetic diversity of offspring $[11,12]$. The flowering patterns of many plants have been shaped to increase the rate of allogamy and avoid inbreeding $[9,10]$. However, there is a specific trade-off between female fitness and male fitness in monoecious plants. Studies show that the production of male flowers requires less investment than the production of female flowers $[6,13]$. For a monoecious plant, the production of a male flower is cheap [6]. When the environment has abundant pollen resources, the 
fitness of female functions is greater than that of male functions [10]; therefore, increasing investment in female functions favors a plant, such as increasing the number of female flowers, increasing the nectar yield, and extending the flowering period $[14,15]$. Pollen availability may limit female success with respect to individual flowers, entire plants (in a season or over a lifetime), or populations [14]. However, environmental stresses can make a plant increase its investment in male functions because that investment may have greater returns [10]. The other side of increasing investment in female functions is that the production of fruit then requires more resources. For mature seeds, more seeds means more resources are required. However, too much fruit and seed production can lead to a reduction in nutrients allocated to each fruit $[16,17]$, which goes against the optimal resource allocation of heredity, i.e., the fitness of offspring is limited $[18,19]$. This status may be more significant when environmental resources are restricted [20]. Therefore, there is a trade-off between the production of female flowers and the production of single fruits or seeds. Male flowers require far fewer resources than female flowers, so in the absence of nutrients or pollen resources, male flowers may be more than female flowers to increase the fitness of plant reproductive success to achieve optimal resource allocation. Consequently, from a plant perspective, the production of cheap male flowers is an economic and effective strategy [6, 21]. However, this long-term strategy is too difficult for plants to implement. When resources for pollination are not limited, it is not clear whether a plant will produce a limited number of female flowers to bear larger fruits that may yield better seeds or whether more female flowers will be produced to maximize the use of resources.

Cucumber plants were chosen to assess the responses of the reproductive allocation strategy of plants in response to pollination strength. Cucumbers are ideal for the study of the sexual expression of plants because they are typical monoecious plants of Cucurbitaceae and have a variety of sexual expressions, such as gynoecious, hermaphroditic, monoecious, and trimonoecious expressions [22]. The diversity of the sexual expression of cucumbers is closely related to environmental factors such as temperature, light, moisture, and nutrient conditions and is also affected by the level of growth-regulating plant substances $[23,24]$. The sexual expression of cucumbers is highly sensitive to the surrounding environment, including internal and external factors. Cucumbers can adjust their sexual expression to achieve the maximum ability to use and allocate environmental resources [23]. An attempt was made in this research to study the response of the sexual expression of cucumbers to the availability of pollen under controlled soil-nutrient conditions, specifically, 1 ) the impact of artificial pollination for improved fruit and seed set in cucumbers and 2) whether there is a trade-off between female flower production and fruit or seed production in response to nutrient allocation and pollen resources.

\section{Results}

\section{Number of male and female flowers}

Nutrient treatment had a significant impact on the number of female flowers but not the number of male flowers (Table 1). There were no significant differences among pollination levels or nutrient levels for male flowers (Table 1) except for a higher peak at the P2 level, which fell and then gradually increased 
with the pollination levels (Fig. 1a). The number of female flowers, was higher at high nutrient levels than at low nutrient levels (Fig. 1b). Different from male flowers, the number of female flowers was significantly affected by pollination, as well as the interaction between pollination and nutrients (Table 1). However, the highest number of female flowers did not correspond with the highest pollination level (Fig. 1b).

Obviously, with the growth of cucumber plants, the flower number increased gradually with pollination day (Fig. 2) (Repeated Measures ANOVA, df $=31, F=15.008, P=0.000<0.05$ ). And also, from the analysis to the changes of female flower number, we still found that the time of pollination had a significant effect on the number changes of female flower (Repeated Measure ANOVA, Huynh-Feldt adjusted F-test, under high nutrient level: $\mathrm{df}=18.15, \mathrm{~F}=1.62, \mathrm{P}=0.04<0.05$, and under low nutrient level: $\mathrm{df}=20.41, \mathrm{~F}=4.67, \mathrm{P}$ $=0.00<0.05$ ). The number of female flowers reached the maximum after 4 days of the end of the pollination experiment (i.e. the 36th day), and decreased on the 11th day after pollination experiment (i.e. the 43th day) (Fig. 2). This indicated that the pollination treatment may have an accumulation effect on the flowering behavior of cucumbers, and the pollination will lead to an increase in the subsequent flowering number of cucumbers.

Although overall analysis showed that the effects of pollination treatments were not significant (Table 1), there were significant effects on female flowers on some days, which mainly appeared during the later stages of the pollination experiment, i.e., the number of female flowers increased with the level of pollination (Fig. 2). Different pollination levels lead to differences in the peak number of female flowers during the pollination experiment, i.e., with the increase in the pollination degree, the number of female flowers gradually increased in the late stage of the pollination experiment, while under low pollination (P1), there was an early decrease in female flowers (Fig. 2). Further, after the pollination experiment, the number of female flowers showed a significant decrease on the 11th day compared with the 4th day (Ttest, $d f=19, t=2.269, p=0.035<0.05$ ) (Fig. 2), while the number of flowers in the control group without pollination did not decrease significantly.

\section{Reproduction set}

Nutrient and pollination treatments significantly affected the total weight of fruits during the pollination experimental stage but did not affect the fruits that were produced after the experiment (Table 1, Fig. 3). Moreover, results showed that the maximum total weight of fruits occurred at the low pollination level under high nutrient treatment, in other words, as the pollination level increased, the weight of total fruits did not increase accordingly. This trend was the same as that of the number of female flowers. At low nutrient levels, the pollination treatment did not significantly change the total weight of fruits compared with the blank control (Fig. 3). Nonetheless, the effect of pollination on a single fruit weight was different from the total weight of fruits per plant. The results showed that in the high nutrient treatment, pollination increased the average weight of a single fruit, and in the third level of the pollination treatment, the weight of a single fruit was maximal and significantly higher than that in the low nutrient treatment (Table 1, Fig. 
4a). The results can be explained by the number of fruits and fruit set. In addition to the weight of fruit, pollination also significantly affected the number of fruit and the percentage fruit set (Table 1, Fig. 4b, c). The patterns of fruit number and relative fruit set were similar to those of the total weight of fruits at the two nutrient levels; the values were greatest at the P1 level, and there was also a small downward fluctuation with the increase in pollination levels (Fig. 4b, c). This means that a continued increase in pollination will reduce the number of fruit, thus decreasing the total weight of fruit per plant; however, because the fruit number decreases, the average weight of a single fruit will increase.

The mean number of days required to grow mature fruit and the fruit diameter and length were also recorded. The results indicated that the effects of the nutrient and pollination treatments were not significant (Table 1, Fig. 5); fruit diameter and length were significantly affected only by the interactions of nutrients and pollination. However, fruit length and fruit diameter increased gradually with pollination levels at a high nutrient level; this trend was not observed at low nutrient levels. In the pollination control and at the P1 level, the fruit diameter and length were higher at low nutrient levels than at high nutrient levels (Fig. 5).

\section{Seed production}

The seed production was significantly affected by nutrients and pollination. At high nutrient levels, the number of seeds per fruit was higher at the P2 and P3 levels than in the control (Fig. 6a). At the low nutrient level, however, the number of seeds per fruit at the P2 level was almost the lowest. Unlike seed number per fruit, the total number of seeds per plant was significantly affected by the interaction between nutrients and pollination (Table 1), and differed from the number of seeds per fruit among pollination levels under low nutrient treatment (Fig. 6b). By contrast, the lowest value was observed at the P2 level, but an increase was observed at the P4 level (Fig. 6b).

\section{Correlation between flowers and fruits and seeds}

Correlation analysis showed that the female flowers were positively correlated with the number of male flowers, number of fruit, weight of fruits per plant, total number of seeds per plant, and the shoot mass but were not correlated with the weight of fruit and the number of seeds per fruit (Table 2). Moreover, the number of fruit per plant was positively correlated with the weight of fruits and the total number of seeds per plant but was uncorrelated or negatively correlated with the weight of fruit, the number of seeds per fruit, and the shoot mass. Additionally, the weight of fruits per plant was also related to the total seed number per plant (Table 2). These results showed that the number of fruit increased with the number of female flowers and that the fruits had a greater weight and a higher number of total seeds; however, there was also a decline in the weight of fruit (Fig. 4a) and the number of seeds. Accordingly, the total number of seeds per plant was negatively correlated with the number of seeds per fruit, and the number of seeds per fruit was positively correlated with the fruit weight (Table 2). These results showed that a high number of fruit per plant can lead to reductions in the weight of a single fruit and that smaller fruit 
produces fewer seeds. Additionally, the shoot mass was negatively correlated with the number of fruit and the total weight of fruits, and the total number of seeds showed a trade-off between vegetation growth and reproductive allocation (Table 2).

\section{Discussion}

The responses of gender expression of monoecious plants to different environments are plastic $[25,26]$. In a nutrient-rich environment, plants tend to increase investment in sexual reproduction $[27,28]$. In this experiment, cucumbers produced significantly more female flowers at high nutrient levels. It can also be said that the cucumbers optimized their use of environmental resources by increasing the number of female flowers. In addition to nutrients, pollen and pollinators should also be regarded as external resource; the richness of these resources can affect plant flowering behavior [29]. Studies have shown that increases in pollinators such as bees can increase the number of flowers per plant, thereby increasing the crop yield as well [30,31]. In this study, the number of female flowers changed to a certain degree with the level of pollination. The study also illustrated the influence of the strength of pollination on the differentiation of female flowers. The peak number of female flowers did not appear at the highest pollination level but at middle levels, which suggests that the response of cucumber female flowers to the intensity of pollination is not a linear increase but will increase or decrease based on the nutrient supply. From the flowering period until the end of the pollination experiment, the number of female flower gradually increased: this was associated with the growth of the plants, but the pollination experiment showed that in the late stage of pollination, the number of female flowers differed significantly among different pollination levels, which suggested that the effect of pollination on plant flowering behavior was mainly on the number of new flowers. This further illustrated that pollination treatment has accumulated effect on cucumber flowering behavior. Increasing the pollination makes plant flowers subsequent increase in the number, but when stop pollination (12 days after pollination), cucumber will reduce the flowering (Fig. 2), it also illustrated that the response of flowering behavior of cucumber to pollen resource is subsequent and short-lived. However, studies on the flowering behavior of plants are less about the response to pollination timeliness and more about the responses to the spatial and temporal distribution pattern of pollen resources $[32,33]$.

The production of male flowers is easier and cheaper than that of female flowers; therefore, plants often produce more male flowers for maximum fitness when resources are sparse [6, 34]. In this study, there were significantly fewer female flowers under low-nutrient conditions, but the number of male flowers remained unchanged. In this way, the ratio of male to female flowers increased, proving that male fitness increases under resource-poor conditions [35]. The pollination treatment did not affect subsequent male flowers; however, the number of male flowers, which did not decrease at different pollination levels, showed a complementary effect on the number of female flowers that decreased under low nutrient conditions after pollination. This compensation effect enables plants to make optimal use of resources such as nutrients and pollen, and to maintain the maximum fitness of plants [36, 37]. 
Studies have shown that pollination can increase crop yield [31,38]. However, there are differences between fruit production and seed production because the former comes is attributed to the ovary of a cucumber plant, and seed production requires the ovule to develop normally after fertilization is complete. For this reason, fruit growth in some cases is not restricted by fertilization; rather, it may be more conducive to the production of fruit if no fertilization occurs [39]. In this experiment, the pollination treatment significantly increased the total weight of plant fruits (Table 2), which was consistent with the number of female flowers and peaked at the P1 level. The results showed that the production of fruit was affected by pollination at a certain level. Studies have shown that plants can increase the concentration of some endogenous hormones (such as ethylene and auxin) after being fertilized and that the hormones can in turn promote the development of the ovary $[40,41]$. In our experiment, the relative number of setting fruit exhibited a trend similar to that observed for the number and weight of fruit, which shows that a high ratio of fruit set may be associated with a high number of fruit as well as a high fruit weight. However, these trends did not increase with the levels of pollination but peaked at the P1 level and then fluctuated with a declining trend, which suggests that excessive pollination can lead to restrained fruit growth and can thereby decrease the relative amount of setting fruit. The percentage of fruit set was the lowest in the control pollination group, but some fruits did develop, which proved that the growth of cucumber fruit is not entirely affected by pollination.

Studies have shown that high levels of pollen on the stigma will cause clogging in pollen tubes and pollen redundancy, called pollen discounting [42]. In our experiment, there were fewer seeds in the fruit at high pollination levels under high-nutrient conditions because of pollen discounting. Excessive pollination cannot result in the development of all seeds; rather, the development of parts of seeds can be limited because of pollen tube blockage. A high pollination level may thus increase the total number of cucumber seeds per plant, but this can lead to a decrease in the number of seeds per fruit. However, this trend changed when the level of soil nutrients was low; plants increased their investment in seed development, although the total number of seeds was not higher than at high nutrient levels, and the number of seeds per fruit was significantly higher at the high pollination levels, i.e., P3 and P5. That is to say, under the condition of sufficient nutrients, increasing pollination will increase the total seed number per plant, but very high levels of pollen will lead to a reduction in the seed number per fruit, while under the condition of insufficient nutrients, pollination will increase the seed number per fruit. Cucumbers thus tend to allocate more nutrients to sexual reproduction to produce more seeds when resources from the external environment are sparse. When resources are abundant, the proportion of investment in the seed set decreases, although the total number of seeds per plant increases because of the increasing number of fruit. During the flowering stage, cucumbers coordinated the ratio of male and female flower number based on the soil nutrient conditions and the intensity of pollination. This trade-off allows cucumbers to maximize their use of resources. Here, if fitness is evaluated by the number of male and female flowers, cucumbers have realized optimal reproductive fitness. However, the growth of fruit and seed development require nutrients, and the demand for nutrients differs during the flowering stage because the production of male and female flowers is also determined by nutrients and pollination. The pattern of male and female flowers in the flowering stage, which optimizes the use of nutrients and pollens, may not realize 
the maximum fitness during the fruiting or seed setting stages. The current study suggests that the number of female flowers is positively correlated with the number of fruit and the total number of seeds but not the weight or number of seeds per fruit. In this way, more female flowers mean more fruits, which can lead to smaller and less developed fruits. The trade-off of plants in the flowering stage may not favor fruit maturity or seed development.

Plant reproductive ecology is the study of the responses of plants with respect to breeding strategies and their impact on evolutionary significance [43]. The universal view is that the response of plant breeding strategies to the external environment is active and positive, the result being that a plant will maximize the use of resources in an environment [19]. However, these studies principally concern the direct responses of plants to the external environment; the response measures include changes in male and female flower differentiation [44], changes in flowering time [45], and special structures of plant reproductive organs in response to the environment [46]. These factors show that the response of plants to the external environment is instant; plants can always reach optimal fitness with respect to environmental conditions. However, studies in this field are limited. The stress response of plants to the environment, whether covering or considering the entire course of plant breeding, is unclear. In the current study, the effects of pollination and nutrient treatment on cucumber should be different. Pollination levels directly affect seed development, and soil nutrient levels directly affect the number of male and female flowers. However, these two types of patterns are competitive in their demands for nutrients, and there is a trade-off between seed and flower production. For this reason, the number of female flowers was not consistent with the number of seeds per fruit in this study. The number of flowers was established during the blooming phase based on the conditions of soil nutrients and other possible factors; however, this response may not be the optimal arrangement for fruit growth and seed maturation, and the pattern of more flowers, more large fruits and more seeds may not emerge. In this experiment, the number of female flowers was consistent with the number of fruit and the total number of seeds but not with the fruit biomass and the number of seeds per fruit, which means that more female flowers will have more fruits, although smaller fruit with fewer seeds. In Cucurbitaceae crops, cultivators may remove secondary-lateral branches to prevent the production of too many female flowers [47]. This may be particularly relevant to watermelon management, where this practice may ensure bigger fruit, especially considering that people usually keep only one fruit per plant $[48,49]$. An increased production of female flowers may later require more resources for increased fruit and seed production. This may not benefit the development of good seeds because fewer resources are allocated to a single fruit. Fitness of plants may be reduced in this manner.

Plants must respond to the external environment by allocating their resources for specific goals. Evaluating the fitness of this type of immediate response does not produce high scores. For example, large numbers of seeds often germinate from a single fecal clump, although competition may leave many delicate seedlings [50]. It may be disadvantageous to the growth of the next generation to evaluate the fitness or adaptation to the environment [50]. However, in the long-term evolutionary process, plants have some strategies that may make up for defects. For example, plants can adjust the number of fruit after flowering by dropping fruit to adapt to the nutrient availability [51]. In this study, cucumbers also 
dropped many fruits after flowering. From this perspective, dropping of fruit may be a type of regulation of fruit growth in response to environmental conditions. Dropping of fruit also illustrates that the layout of plants with respect to the number of flowers during the flowering stage may not be suitable for the growth of fruits and seeds during a later stage.

\section{Conclusions}

From the study to cucumber flower differentiation under different levels of nutrient and pollination, we found that the number of female flowers can response to nutrients and pollination resources, namely the number of female flowers can increase along with the increase of nutrient concentration, and also can achieve a higher level under a certain degree of pollination, but this pattern of resource allocation of male and female flower number to nutrients and pollination resource is not the most suitable to the fruit growth and seed development of subsequent. Therefore, the study suggests that plant response to the external environment is not a long-term response from the perspective of overall resource allocation. Response to the external environment can be described as an instantaneous stress reaction. This stress response is also meaningful in the evolutionary perspective, and this plasticity of regulation allows organisms to adapt to changes in their environment $[52,53]$.

However, our conclusion is based only on the study of domesticated cucumber varieties. We still do not know whether wild plants or wild cucumbers under natural conditions will be more adaptable to environmental resources than artificial varieties. This information is needed to properly adjust the allocation of resources between flowering and fruit development. The flowering and fruit production of wild plants are more sensitive to the external environment than domesticated varieties because of their higher number of phenotypes [54], which may further verify the immediacy of plant response to environmental resources. However, more research on wild plant species is needed to confirm this.

\section{Methods}

\section{Materials}

Cucumber (Cucumis sativus: Cucurbitaceae), a widely-cultivated annual plant, is ideal for studying the effects of pollinators on plant performance, because of its typical monoecious characteristics [55]. Male flowers, which are solitary, grow from leaf axils, and the calyx is tube-like, narrow, bell-shaped, and 8-10 $\mathrm{mm}$ in length. The corolla is yellow and $2 \mathrm{~cm}$ in length. Male flowers have three stamens with 3-4 mm anthers. Female cucumber flowers are similar to the male flowers but have a spindle-shaped ovary underneath that has significant thorns. In general, cucumber is monoecious and reliant on pollinators for fertilization. Both male and female flowers remain open for a single day and are visited by a variety of generalist pollinators [55]. Total flower production varies according to the growing conditions, but male flowers usually outnumber females by at least tenfold [55]. The cucumber fruit is cylindrical and approximately $10-30 \mathrm{~cm}$ long. Cucumbers require well-drained soil with $80-90 \%$ humidity for optimal 
growth, and they require $60-70 \%$ substrate humidity after the seedling stage. Moreover, cucumbers thrive well in optimal nutrient levels but not in an environment with an overabundance of nutrients [56].

\section{Cultivation}

Wild cucumbers have various phenotypes, and they show different shapes even under the same conditions of cultivation. Therefore, in order to reduce experimental errors, artificial domesticated varieties were adopted in this study. All cultivation and experiments were conducted in the College of Natural Sciences greenhouse (CNS greenhouse) of Massachusetts, USA. At first, 120 cucumber seeds (Cucumis sativus; Marketmore 76, Johnny's Selected Seeds Company, Fairfield, ME, U.S.) were sown in the cell trays in the greenhouse at maximum and minimum temperatures of $24^{\circ} \mathrm{C}$ and $18^{\circ} \mathrm{C}$, respectively, using ProMix HP potting soil (Pro-Mix HP Mycorrhizae Company, Québec, Canada). Plants were watered daily as needed. After the seedlings grown at least two true leaves, each seedling was then transplanted into a 4" pot $(0.57 \mathrm{~L})$, also using ProMix HP potting soil. On December 22 of the same year, Marathon II (OHP Company, Vineland, NJ, U.S.) was used as a soil drench at a rate of $1.6 \mathrm{ml} / \mathrm{l}$ to control insect pests.

\section{Experimental design}

The experiment consisting of fertilizer ( 2 levels) and pollination ( 6 levels) concentrations was carried as a full factorial design. There were 10 replications for each of the 12 treatment combinations, resulting in a total of 120 plants. Fast-release Osmocote fertilizer with a 20:20:20 N:P:K ratio (The Scotts Company LLC. Marysville, OH, U.S.), was initially added at concentrations of $150 \mathrm{ppm}$ and $300 \mathrm{ppm}$, respectively, when the plants were still in the seedling stage, i.e., before final transplantation [57, 58](Morenoet al., 1998; Huet al., 2012). When the plants had 5-6 leaves, each seedling was transplanted into a $7.57 \mathrm{~L} \mathrm{pot,}$ and fast-release fertilizer was added once based on the previous nutrient settings. After one week, Osmocote slow-release fertilizer was added (N:P:K ratio 14:14:14) at a rate of $12 \mathrm{~g}$ per plant in the highnutrient treatment group and $6 \mathrm{~g}$ per plant in the low-nutrient treatment group. These levels were consistent with Osmocote fertilizer guidelines for potted plants.

Pollination treatments commenced shortly after the female flowers appeared. An additional 20 nonexperimental cucumber plants were also planted to serve as pollen donors. Each pollen donor was grown and fertilized in the same way as plants in the high-nutrient treatment group.

\section{Male and female flower production}

The numbers of male and female flowers were recorded daily once plants began flowering. Because cucumber flowers open in the morning and wither the following morning, daily counts were strongly indicative of male and female flower production. All flowers were counted until the end of the pollination treatment. The records included the number of flowers that grew in one month. Additionally, the number 
of flowers was recorded twice to assess the persistent responses of cucumbers, after pollination treatments.

\section{Pollination settings}

Previous studies on cucumber pollination generally placed the pollen directly on the flower with a toothpick or a cotton paintbrush [59]. However, this method is not conducive to accurate control of the pollen concentration. Instead, we used a sucrose-pollen solution that has been used in other plants [60, 61]. The anthers were collected from 10 male flowers from the pollen donors each day. All stamens were cut and placed in a tube with $10 \mathrm{ml}$ of $10 \%$ sucrose solution [61], and the tube was then vortexed for 2 min. This solution was used for the highest level of pollen concentration (Level 5) and was serially diluted to create the 4 lower pollen concentration solutions. For each dilution, the volume of solution was doubled (and the concentration of pollen was thus halved) by adding an equivalent amount of sucrose solution to a portion of the pollen solution. A hemocytometer was used to quantify the concentration of pollen in 5 samples from the highest concentration solution $[62,63]$. The average number of pollen grains in one square $\left(1 \mathrm{~mm}^{2}\right)$ was $2.2 \pm 0.84$ grains, and the concentration from the formula was $110 \mathrm{grains} / \mu \mathrm{l}$. All female flowers on each plant were pollinated every day for one month by placing $20 \mu$ of the pollen solution on the stigma by pipette. In the highest pollination treatment, the total number of pollen grains was 2,200; accordingly, the total number of pollen grains was expected to be $1,100,550,275$, and 137.5 grains for other treatment levels and zero in the controls ( $20 \mu \mathrm{l}$ sucrose solution without pollen). Each pollinated female flower was labeled with the date of pollination to allow calculation of the days required for fruit development. The pollination treatment was performed from 8:00 to 10:00a.m every day for 32 days during flowering stage.

\section{Fruit production}

All fruits were harvested when they reached a length of $18 \mathrm{~cm}$ or one month after the end of the pollination treatments, whichever indicated maturity, beyond this length, or after one month when fruits began to turn yellow and decay [55]. Two types of fruits were recorded after the pollination experiment, pollinated and non-pollinated. At harvest, the date, fresh weight, length, and diameter of each fruit were recorded. Then, the fruits were cut in half length-wise, the seeds visible in both halves were counted, and this value was averaged, first per fruit and then per plant [55]. The seed counts were used to evaluate the ability of the fruit to produce seeds. Fruit set was calculated as the proportion of female flowers that produced fruit. Fruit weight, fruit length, diameter, and seed counts were averaged per plant so that each plant could be treated as a unit of replication. After fruit harvest, all the above-ground parts of the plants were harvested, air-dried in sunlight for 15 days, and weighed.

\section{Data analysis}


Results were analyzed using general linear models (GLM, SAS 9.3; SAS Institute, Cary, NC, U.S.) for numbers of male and female flowers, fruit weight, fruit size, number of seeds, and above-ground plant mass, and nutrient and pollination treatments and their interactions served as independent variables. Post hoc comparisons between treatments were conducted with Tukey's HSD test. Response variables were averaged per plant so that individual plants could be treated as units of replication. Three plants that were sick and grew poorly during the experiment were excluded. All the response variables were transformed to meet the assumptions of normality and homogeneity of variance by square root transformation, seed number was square-root transformed, and fruit number was arcsine square-root transformed. Normality was confirmed and homogeneity of variance verified with Levene's test. The number of flowers in cucumber changed daily with cucumber growth. Therefore, in order to avoid the influence of cucumber growth time, we took the un-pollinated cucumber as the reference, and carried out variance analysis on the difference between the number of female flowers of cucumber under each pollination level and the control, and we try to analyze the difference of the change amount of female flowers of cucumber under different pollination levels. Here, we used One-way Repeated Measure ANOVA to analyze the differences of the changes of female flowers in each nutrient level, with only pollination as independent variables, and the number of daily changes in female flowers as dependent variables, the factor of days is repeated measure factor. And just to make it a little bit more intuitive, we just plot the average number of flowering every four days of pollination treatment and observe the change of the number of female flowers with days. Correlation analysis of cucumber flower, fruit, and seed traits was based on Pearson's correlation coefficients. Results are presented as non-transformed means. Significance values in the text are at $p<0.05$, unless stated otherwise.

\section{Abbreviations}

GLM: general linear model; RH: relative humidity; HSD: honestly significant difference; ANOVA: analysis of variance; CNS: the college of natural sciences of University of Massachusetts

\section{Declarations}

\section{Acknowledgments}

We thank Prof. Lynn S. Adler for her help in designing the experiment. Mr. J. Christopher, Mr. J. Blanchard, personnel at the College of Natural Sciences greenhouse (CNS greenhouse) at the University of Massachusetts and Prof. Adler's laboratory personnel are acknowledged for their help in the greenhouse. We also thank S. Connon for sample collection and measurement and E. Palmer-Young, M. Boyer, M. Tjiurutue, L. Doubleday, and M. Ha for help throughout the experiment.

\section{Author's contributions}


LG conceived, designed and conducted the experiment. LG wrote the manuscript. All authors contributed critically to the drafts and gave final approval for publication.

\section{Funding}

This work was supported by Adler's lab and the Chinese Academy of Sciences Scholarship Council; additional funding was supported by the National Natural Science Foundation of China (Grant No. 31470451). The funding bodies did not participate in designing the study, data collection, analysis, interpretation of the results or writing the manuscript.

\section{Availability of data and materials}

The data sets used and/or analyzed during the current study are available from the corresponding author on reasonable request.

\section{Ethics approval and consent to participate}

There was no requirement to seek ethical approval to carry out the work described above.

\section{Consent for publication}

Not applicable.

\section{Competing interests}

The authors declare that they have no competing interests.

\section{References}

1.Zhang T, Tan DY. Adaptive significances of sexual system in andromonoecious Capparis spinosa (Capparaceae). J Syst Evol. 2008; 46(6):861-873.

2.Antonovics J, Ellstrand NC. Experimental studies of the evolutionary significance of sexual reproduction.1. A test of the frequency-dependent selection hypothesis. Evolution. 1984; 38(1):103-115.

3.Zhang DY. Resource allocation and the evolution of self-fertilization in plants. Am Nat. 2000; 155(2):187-199.

4.Strauss SY. Floral characters link herbivores, pollinators, and plant fitness. Ecology. 1997; 78(6):16401645. 
5.Couso LL, Fernandez RJ. Phenotypic plasticity as an index of drought tolerance in three Patagonian steppe grasses. Ann Bot-London. 2012; 110(4):849-857.

6.Peruzzi L, Mancuso E, Gargano D. Males are cheaper, or the extreme consequence of size/agedependent sex allocation: sexist gender diphasy in Fritillaria montana (Liliaceae). Bot J Linn Soc. 2012; 168(3):323-333.

7.Atlan A, Hornoy B, Delerue F, Gonzalez M, Pierre JS, Tarayre M. Phenotypic plasticity in reproductive traits of the perennial shrub ulex europaeus in response to shading: A multi-year monitoring of cultivated clones. Plos One. 2015; 10(9):e0137500.

8.Sun S, Zhang DY, Ives AR, Li QJ. Why do stigmas move in a flexistylous plant? J Evolution Biol. 2011; 24(3):497-504.

9.Bai WN, Zhang DY. Sexual interference in coseual plants and its evolutionary impliactions. Acta Phytoeco Sin. 2005; 29(4):672-679.

10.Zhang DY. Plant Life-History Evolution and Reproductive Ecology. Beijing: Science Press; 2003. p. 101-189.

11.Agren J. Population size, pollinator limitation, and seed set in the self-incompatible herb Lythrum salicaria. Ecology. 1996; 77(6):1779-1790.

12.Sakai S, Ishii HS. Why be completely outcrossing? Evolutionarily stable outcrossing strategies in an environment where outcross-pollen availability is unpredictable. Evol Ecol Res. 1999; 1(2):211-222.

13.Bertin RI. The evolution and maintenance of andromonoecy. Evolu Theor. 1982; 6:25-32.

14.Burd M. Bateman Principle and Plant Reproduction - the Role of Pollen Limitation in Fruit and Seed Set. Bot Rev. 1994; 60(1):83-139.

15.Goldman DA, Willson MF. Sex allocation in functionally hermaphroditic plants - a review and critique. Bot Rev. 1986; 52(2):157-194.

16.Ganeshaiah KN, Shaanker RU. Seed abortion in wind-dispersed pods of dalbergia-sissoo - maternal regulation or sibling rivalry. Oecologia. 1988; 77(1):135-139.

17.Marcelis LFM, Heuvelink E, Hofman-Eijer LRB, Den Bakker J, Xue LB. Flower and fruit abortion in sweet pepper in relation to source and sink strength. J Exp Bot. 2004; 55(406):2261-2268.

18.Rosenheim JA, Alon U, Shinar G. Evolutionary balancing of fitness-limiting factors. Am Nat. 2010; 175(6):662-674.

19.Schreiber SJ, Rosenheim JA, Williams NW, Harder LD. Evolutionary and ecological consequences of multiscale variation in pollen receipt for seed production. Am Nat. 2015; 185(1):E14-E29. 
20.Lee TD. Patterns of fruit and seed production. In: Lovett-Doust J, Lovett-Doust L, editors. Plant Reproductive Ecology. New York: Oxford University Press; 1988. p. 179-202.

21.Cranston BH, Callaway RM, Monks A, Dickinson KJM. Gender and abiotic stress affect communityscale intensity of facilitation and its costs. J Ecol. 2012; 100(4):915-922.

22.Song YP, Ma KF, Ci D, Chen QQ, Tian JX, Zhang DQ. Sexual dimorphic floral development in dioecious plants revealed by transcriptome, phytohormone, and DNA methylation analysis in Populus tomentosa. Plant Mol Biol. 2013; 83(6):559-576.

23.Bai SN, Xu ZH. Unisexual cucumber flowers, sex and sex differentiation. Int Rev Cell Mol Biol. 2013; 304(304):1-55.

24.Nicodemo D, Malheiros EB, De Jong D, Couto RHN. Enhanced production of parthenocarpic cucumbers pollinated with stingless bees and Africanized honey bees in greenhouses. Semin-Cienc Agrar. 2013; 34:3625-3633.

25.Dorken ME, Barrett SCH. Gender plasticity in Sagittaria sagittifolia (Alismataceae), a monoecious aquatic species. Plant Syst Evol. 2003; 237(1-2):99-106.

26.Golenberg EM, West NW. Hormonal interactions and gene regulation can link monoecy and environmental plasticity to the evolution of dioecy in plants. Am J Bot. 2013; 100(6):1022-1037.

27.Paquin V, Aarssen LW. Allometric gender allocation in Ambrosia artemisiifolia (Asteraceae) has adaptive plasticity. Am J Bot. 2004; 91(3):430-438.

28.Van Drunen WE, Dorken ME. Trade-offs between clonal and sexual reproduction in Sagittaria latifolia (Alismataceae) scale up to affect the fitness of entire clones. New Phytol. 2012; 196(2):606-616.

29. Halpern SL, Adler LS, Wink M. Leaf herbivory and drought stress affect floral attractive and defensive traits in Nicotiana quadrivalvis. Oecologia. 2010; 163(4):961-971.

30.Groeneveld JH, Tscharntke T, Moser G, Clough Y. Experimental evidence for stronger cacao yield limitation by pollination than by plant resources. Perspect Plant Ecol. 2010; 12(3):183-191.

31.Motzke I, Tscharntke T, Wanger TC, Klein AM. Pollination mitigates cucumber yield gaps more than pesticide and fertilizer use in tropical smallholder gardens. J Appl Ecol. 2015; 52(1):261-269.

32.Chen $M$, Zuo XA. Pollen limitation and resource limitation affect the reproductive success of Medicago sativa L. Bmc Ecol. 2018; 18.

33.Jacome-Flores ME, Delibes M, Wiegand T, Fedriani JM. Spatio-temporal arrangement of Chamaerops humilis inflorescences and occupancy patterns by its nursery pollinator, Derelomus chamaeropsis. Ann Bot-London. 2018; 121(3):471-482. 
34.Vallejo-Marin M, Rausher MD. The role of male flowers in andromonoecious species: Energetic costs and siring success in Solanum carolinense L. Evolution. 2007; 61(2):404-412.

35.Bartkowska MP, Johnston MO. The sexual neighborhood through time: competition and facilitation for pollination in Lobelia cardinalis. Ecology. 2014; 95(4):910-919.

36.Rocheta M, Sobral R, Magalhaes J, Amorim MI, Ribeiro T, Pinheiro M, Egas C, Morais-Cecilio L, Costa MMR. Comparative transcriptonnic analysis of male and female flowers of monoecious Quercus suber. Front Plant Sci. 2014; 5.

37.Teixido AL, Valladares F. Pollinator-mediated phenotypic selection does not always modulate flower size and number in the large-flowered Mediterranean shrub Cistus ladanifer (Cistaceae). Bot J Linn Soc. 2014; 176(4):540-555.

38.Stanley DA, Gunning D, Stout JC. Pollinators and pollination of oilseed rape crops (Brassica napus L.) in Ireland: ecological and economic incentives for pollinator conservation. J Insect Conserv. 2013; 17(6):1181-1189.

39.Dittmar PJ, Monks DW, Schultheis JR. Maximum potential vegetative and floral production and fruit characteristics of watermelon pollenizers. Hortscience. 2009; 44(1):59-63.

40.El-Sharkawy I, Sherif SM, Jones B, Mila I, Kumar PP, Bouzayen M, Jayasankar S. TIR1-like auxinreceptors are involved in the regulation of plum fruit development. J Exp Bot. 2014; 65(18):5205-5215.

41.Yu JQ, Li Y, Qian YR, Zhu ZJ. Changes of endogenous hormone level in pollinated and N-(2chloropyridyl)-N '-phenylurea (CPPU)-induced parthenocarpic fruits of Lagenaria leucantha. J Hortic Sci Biotech. 2001; 76(2):231-234.

42.Zhang AQ, Tan DY, Zhu JZ. The cross-fertilization mechanism and reproductive interference of selfpollen of Medicago varia 'Xinmu No. 1'. J Syst Evol. 2008; 46(6):856-860.

43.Doust JL, Doust LL. Plant Reproductive Ecology. New York: Oxford university press; 1988.

44. Hemborg AM, Karlsson PS. Sexual differences in biomass and nutrient allocation of first-year Silene dioica plants. Oecologia. 1999; 118(4):453-460.

45.Ashman TL, Baker I. Variation in floral sex allocation with time of season and currency. Ecology. 1992; 73(4):1237-1243.

46.Li QJ, Xu ZF, Kress WJ, Xia YM, Zhang L, Deng XB, Gao JY, Bai ZL. Pollination - flexible style that encourages outcrossing. Nature. 2001; 410(6827):432-432.

47.Low JE, Aslund MLW, Rutter A, Zeeb BA. The effects of pruning and nodal adventitious roots on polychlorinated biphenyl uptake by Cucurbita pepo grown in field conditions. Environ Pollut. 2011; 
159(3):769-775.

48.Choi EY, Cho IH, Moon JH, Woo YH. Impact of secondary-lateral branch removal during watermelon production. Hortic Environ Biote. 2012; 53(1):24-31.

49.Nabizadeh E, Taherifard E, Gerami F. Effect of pruning lateral branches on four varieties of medicinal castor bean plant (Ricinuscommunis L.) yield, growth and development. J Med Plants Res. 2011; 5(24):5828-5834.

50.Loiselle BA. Seeds in droppings of tropical fruit-eating birds -importance of considering seed composition. Oecologia. 1990; 82(4):494-500.

51.Marsal J, Basile B, Solari L, DeJong TM. Influence of branch autonomy on fruit, scaffold, trunk and root growth during Stage III of peach fruit development. Tree Physiol. 2003; 23(5):313-323.

52.Sutherland S. Patterns of fruit-set - what controls fruit-flower ratios in plants. Evolution. 1986; 40(1):117-128.

53.Burd M. Offspring quality in relation to excess flowers in Pultenaea gunnii (Fabaceae). Evolution. 2004; 58(10):2371-2376.

54.Gepts P. Crop domestication as a long-term selection experiment. In: Janick J, editor. Plant Breeding Reviews. New Jersey: John Wiley \& Sons Inc; 2004. p.1-44.

55.Barber NA, Adler LS, Bernardo HL. Effects of above- and belowground herbivory on growth, pollination, and reproduction in cucumber. Oecologia. 2011; 165(2):377-386.

56.Ward GM. Growth and nutrient absorption in greenhouse tomato and cucumber. P Am Soc Hortic Sci. 1967; 90(Jun):335-341.

57.Hu YC, Song ZW, Lu WL, Poschenrieder C, Schmidhalter U. Current soil nutrient status of intensively managed greenhouses. Pedosphere. 2012; 22(6):825-833.

58.Moreno DA, Pulgar G, Ruiz JM, Villora G, Romero L. Optimum nutrient range in cucumber (Cucumis sativus L. Cv. Brunex F-1 plants): I. Nitrogen and phosphorus parameters. Phyton-Int J Exp Bot. 1998; 63(1-2):191-195.

59.Baker DN, Kanekal SG, Li X, Monk SP, Goldstein J, Burch JL. An extreme distortion of the Van Allen belt arising from the 'Hallowe'en' solar storm in 2003. Nature. 2004; 432(7019):878-881.

60.Dinesh MR, Rekha A, Ravishankar K, Praveen KS, Santosh LC. Breaking the intergeneric crossing barrier in papaya using sucrose treatment. Sci Hortic-Amsterdam. 2007; 114(1):33-36.

61. Owuor BO, Owino F. Control pollination and pollen management in Sebania sesban (L) Merr. Euphytica. 1993; 70(3):161-165. 
62.Dalkilic Z, Mestav HO. In vitro pollen quantity, viability and germination tests in quince. Afr J Biotechnol. 2011; 10(73):16516-16520.

63.Godini A. Counting pollen grains of some almond cultivars by means of an haemocytometer. Riv Ortoflorofrutt It. 1981; 65(3):173-178.

\section{Tables}

Table 1 ANOVA showing the differences in numbers of flower, number of fruit, fruit set, fruit size, fruit weight and number of seeds among different nutrient and pollination treatments. 


\begin{tabular}{|c|c|c|c|}
\hline Factors & Dependent v. & df F & $P$ value \\
\hline \multirow[t]{16}{*}{ Nutrient } & No. male flowers & 311.48 & 0.084 \\
\hline & No. female flowers & 311.306 & $0.041^{*}$ \\
\hline & No. male flowers on the 4 th day after pollination & 12.50 & 0.117 \\
\hline & No. male flowers on the 11 th day after pollination & 110.60 & $0.002^{* *}$ \\
\hline & No. female flowers on the 4 th day after pollination & 111.06 & $0.001^{* *}$ \\
\hline & No. female flowers on the 11 th day after pollination & 115.45 & $0.021^{*}$ \\
\hline & Weight of fruits per plant (Non-pollinated fruits) & 11.20 & 0.278 \\
\hline & Weight of fruits per plant (Pollinated fruits) & 116.59 & $0.000^{* * *}$ \\
\hline & Weight of fruit & 10.06 & 0.810 \\
\hline & No. fruit & 118.11 & $0.000^{* * *}$ \\
\hline & Percentage fruit set & 17.03 & $0.009^{*}$ \\
\hline & Mean days of fruit growing & 10.15 & 0.702 \\
\hline & Mean diameter of fruit & 10.23 & 0.635 \\
\hline & Mean length of fruit & 10.04 & 0.839 \\
\hline & Total no. seeds per plant & 115.06 & $0.000^{* * *}$ \\
\hline & No. of seeds per fruit & 10.09 & 0.766 \\
\hline \multirow[t]{16}{*}{ Pollination } & No. male flowers & 310.88 & 0.823 \\
\hline & No. female flowers & 311.628 & $0.042^{*}$ \\
\hline & No. male flowers on the 4 th day after pollination & 50.97 & 0.437 \\
\hline & No. male flowers on the 11 th day after pollination & $5 \quad 1.82$ & 0.115 \\
\hline & No. female flowers on the 4 th day after pollination & 51.07 & 0.382 \\
\hline & No. female flowers on the 11 th day after pollination & 152.48 & $0.037^{*}$ \\
\hline & Weight of fruits per plant (Non-pollinated fruits) & 50.63 & 0.681 \\
\hline & Weight of fruits per plant (Pollinated fruits) & 52.39 & $0.043^{*}$ \\
\hline & Weight of fruit & 51.64 & 0.157 \\
\hline & No. fruit & 52.49 & $0.036^{*}$ \\
\hline & Percentage fruit set & 52.62 & $0.029^{*}$ \\
\hline & Mean days of fruit growing & 51.59 & 0.173 \\
\hline & Mean diameter of fruit & 50.76 & 0.580 \\
\hline & Mean length of fruit & 51.15 & 0.339 \\
\hline & Total no. seeds per plant & 56.78 & $0.000^{* * *}$ \\
\hline & No. of seeds per fruit & 56.53 & $0.000^{* * *}$ \\
\hline \multicolumn{2}{|c|}{ Nutrients and Pollination No. male flowers } & 311.03 & 0.405 \\
\hline & No. female flowers & 312.177 & $0.003^{*}$ \\
\hline & No. male flowers on the 4 th day after pollination & 50.20 & 0962 \\
\hline & No. male flowers on the 11 th day after pollination & 51.27 & 0.284 \\
\hline & No. female flowers on the 4 th day after pollination & 50.68 & 0.637 \\
\hline & No. male flowers on the 11 th day after pollination & 51.13 & 0.349 \\
\hline & Weight of fruits per plant (Non-pollinated fruits) & 50.30 & 0.915 \\
\hline & Weight of fruits per plant (Pollinated fruits) & 51.44 & 0.215 \\
\hline & Weight of fruit & 51.40 & 0.232 \\
\hline & No. fruit & 51.32 & 0.262 \\
\hline & Percentage fruit set & 50.91 & 0.476 \\
\hline & Mean days of fruit growing & 51.40 & 0.235 \\
\hline & Mean diameter of fruit & 52.99 & $0.016^{*}$ \\
\hline & Mean length of fruit & 52.12 & 0.072 \\
\hline & Total no. seeds per plant & 51.30 & 0.564 \\
\hline & No. of seeds per fruit & 50.78 & 0.270 \\
\hline
\end{tabular}

Table 2 Correlation analysis of cucumber flower, fruit, and seed traits using Pearson's linear simple correlation with two-tailed $P$ values. 


\begin{tabular}{|c|c|c|c|c|c|c|c|c|}
\hline & & $\begin{array}{l}\text { Female } \\
\text { flowers }\end{array}$ & $\begin{array}{l}\text { No. } \\
\text { fruit }\end{array}$ & $\begin{array}{l}\text { Non-pollinated } \\
\text { female flowers }\end{array}$ & $\begin{array}{l}\text { Male } \\
\text { flowers }\end{array}$ & $\begin{array}{l}\text { Non- } \\
\text { pollinated } \\
\text { male flowers }\end{array}$ & $\begin{array}{l}\text { Weight of } \\
\text { fruits per } \\
\text { plant }\end{array}$ & $\begin{array}{l}\text { Total } \\
\text { seeds per } \\
\text { plant }\end{array}$ \\
\hline \multirow[t]{3}{*}{ No. fruit } & $r$ & $0.337^{* *}$ & & & & & & \\
\hline & $p$ & 0.000 & & & & & & \\
\hline & $n$ & 117 & & & & & & \\
\hline \multirow{3}{*}{$\begin{array}{l}\text { Non-pollinated } \\
\text { female flowers }\end{array}$} & $r$ & $0.349^{* *}$ & 0.049 & & & & & \\
\hline & $p$ & 0.000 & 0.601 & & & & & \\
\hline & $n$ & 117 & 117 & & & & & \\
\hline \multirow[t]{3}{*}{ Male flowers } & $r$ & $0.451^{* *}$ & 0.088 & $0.246^{* *}$ & & & & \\
\hline & $p$ & 0.000 & 0.345 & 0.007 & & & & \\
\hline & $n$ & 117 & 117 & 117 & & & & \\
\hline \multirow{3}{*}{$\begin{array}{l}\text { Non-pollinated } \\
\text { male flowers }\end{array}$} & $r$ & $0.259^{* *}$ & -0.173 & 0.147 & $0.444^{* *}$ & & & \\
\hline & $p$ & 0.005 & 0.063 & 0.113 & 0.000 & & & \\
\hline & $n$ & 117 & 117 & 117 & 117 & & & \\
\hline \multirow{3}{*}{$\begin{array}{l}\text { Weight of fruits } \\
\text { per plant }\end{array}$} & $r$ & $0.337^{* *}$ & $.892^{* *}$ & -0.053 & 0.135 & -0.152 & & \\
\hline & $p$ & 0.000 & 0.000 & 0.569 & 0.145 & 0.101 & & \\
\hline & $n$ & 117 & 117 & 117 & 117 & 117 & & \\
\hline \multirow{3}{*}{$\begin{array}{l}\text { Total seeds per } \\
\text { plant }\end{array}$} & $r$ & $0.236^{*}$ & $0.721^{* *}$ & -0.033 & 0.139 & -0.146 & $0.849^{* *}$ & \\
\hline & $p$ & 0.01 & 0.000 & 0.725 & 0.136 & 0.116 & 0.000 & \\
\hline & $n$ & 117 & 117 & 117 & 117 & 117 & 117 & \\
\hline \multirow[t]{3}{*}{ Shoot mass } & $r$ & $0.387^{* *}$ & -0.039 & $0.380^{* *}$ & $0.293^{* *}$ & $0.523^{* *}$ & -0.065 & -0.067 \\
\hline & $p$ & 0.000 & 0.681 & 0.000 & 0.001 & 0.000 & 0.488 & 0.473 \\
\hline & $n$ & 117 & 117 & 117 & 117 & 117 & 117 & 117 \\
\hline \multirow[t]{3}{*}{ Seeds per fruit } & $\mathrm{r}$ & 0.051 & -0.034 & 0.135 & 0.124 & -0.007 & -0.057 & -0.042 \\
\hline & $\mathrm{p}$ & 0.593 & 0.714 & 0.146 & 0.182 & 0.942 & 0.539 & 0.656 \\
\hline & $\mathrm{n}$ & 117 & 117 & 117 & 117 & 117 & 117 & 117 \\
\hline \multirow[t]{3}{*}{ Weight of Fruit } & $\mathrm{r}$ & 0.019 & 0.077 & 0.093 & 0.101 & -0.051 & 0.053 & 0.012 \\
\hline & $\mathrm{p}$ & 0.861 & 0.465 & 0.379 & 0.336 & 0.629 & 0.614 & 0.911 \\
\hline & $\mathrm{n}$ & 92 & 92 & 92 & 92 & 92 & 92 & 92 \\
\hline
\end{tabular}

Figures 


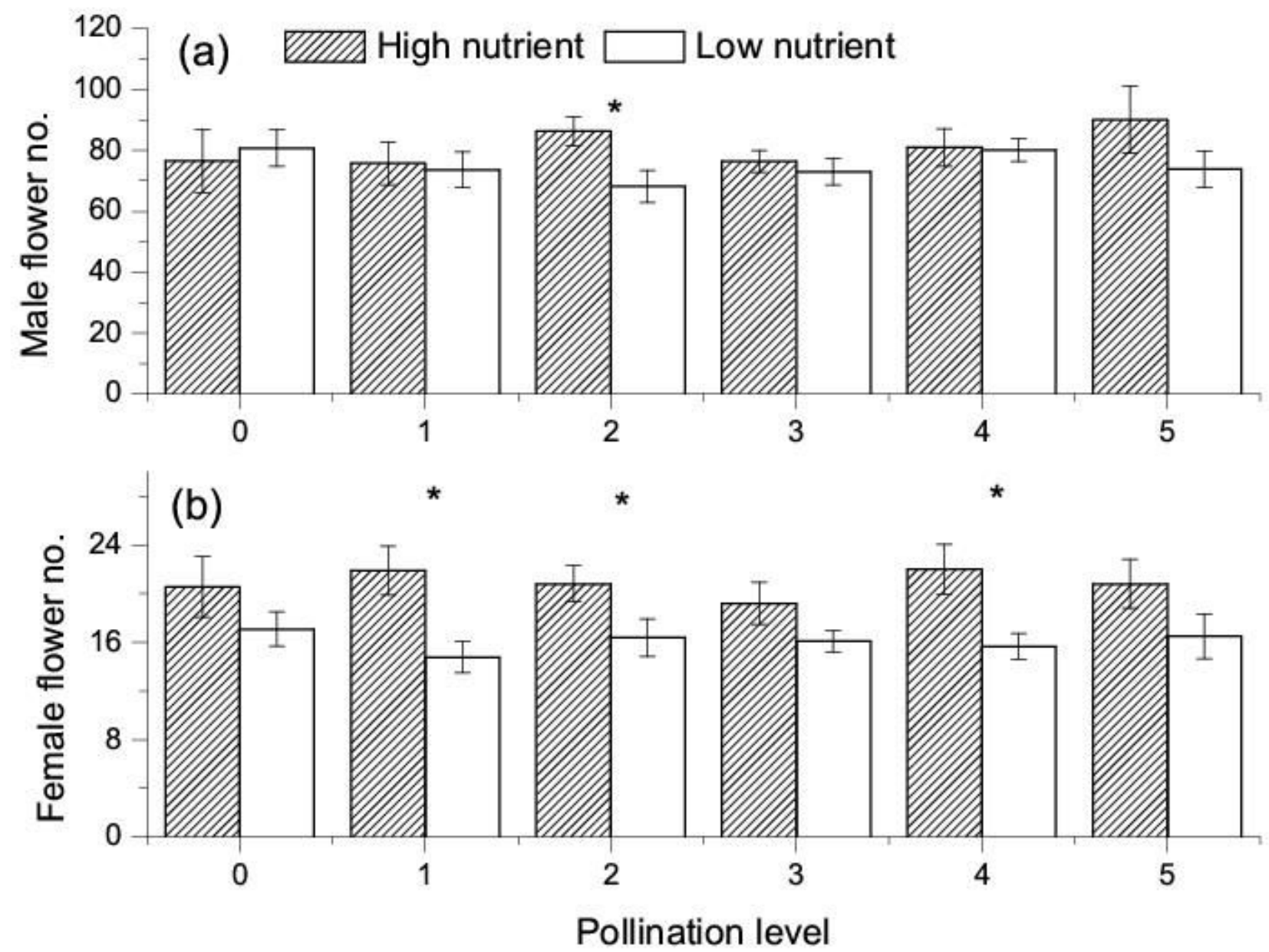

Figure 1

Total (a) male and (b) female flowers per plant under different nutrient and pollination treatments. Plots show mean $\pm S E$, and asterisks above the columns show significance between high and low nutrient treatments analyzed using two-way ANOVA. 


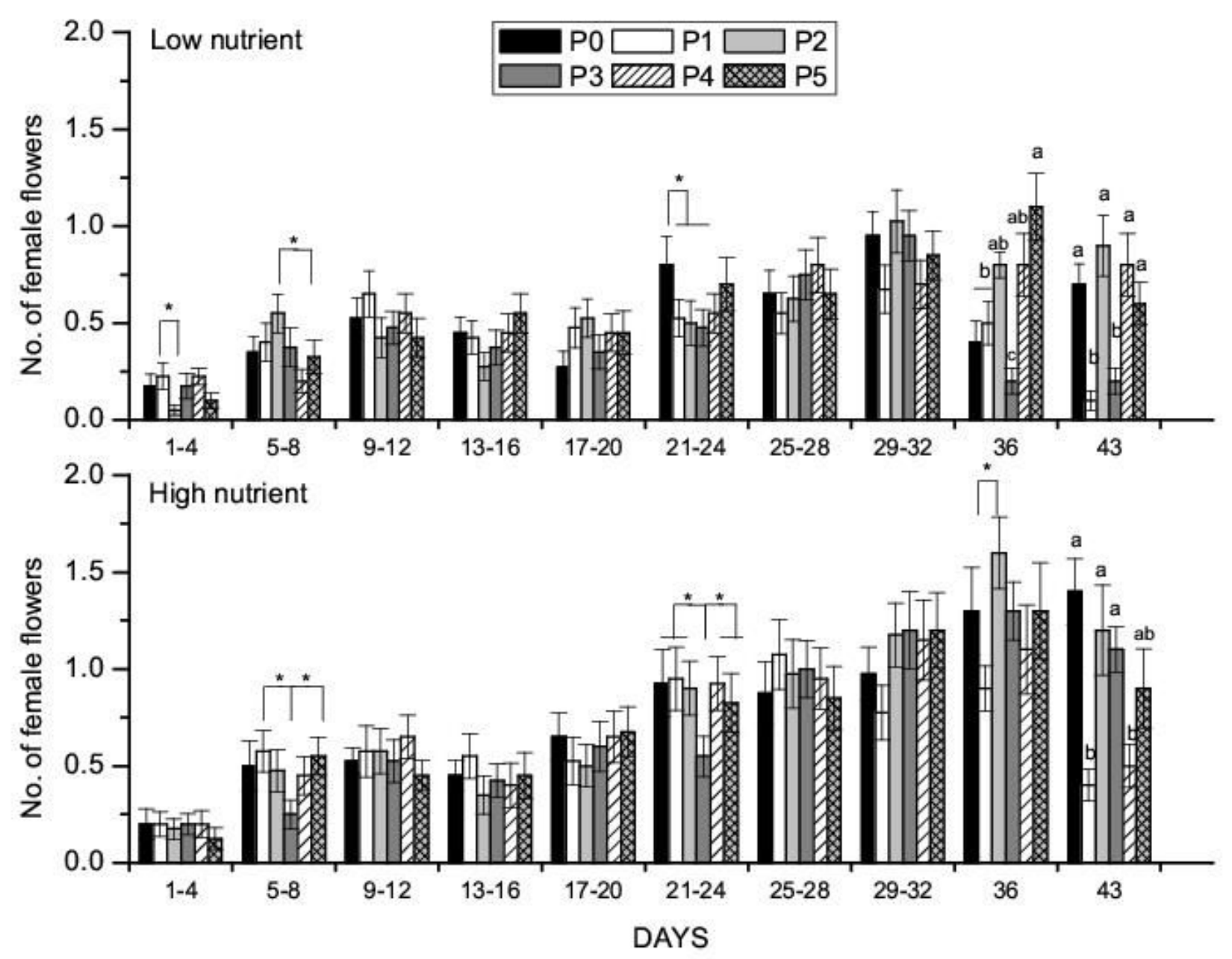

Figure 2

The average number of female flowers counted every 4 days during the pollination treatments and the 2 records of female flowers after the pollination treatments. Plots show the mean $\pm S E$, and different letters above columns indicate significant differences among different pollination levels. No letters indicate that the number of female flowers at this pollination level was not different from that of other pollination levels. Asterisk on the top of the column means two or several data pairs are different. The data were divided into high and low nutrient group, and analyzed with one-way ANOVA and the Tukey test for multiple comparison testing. 


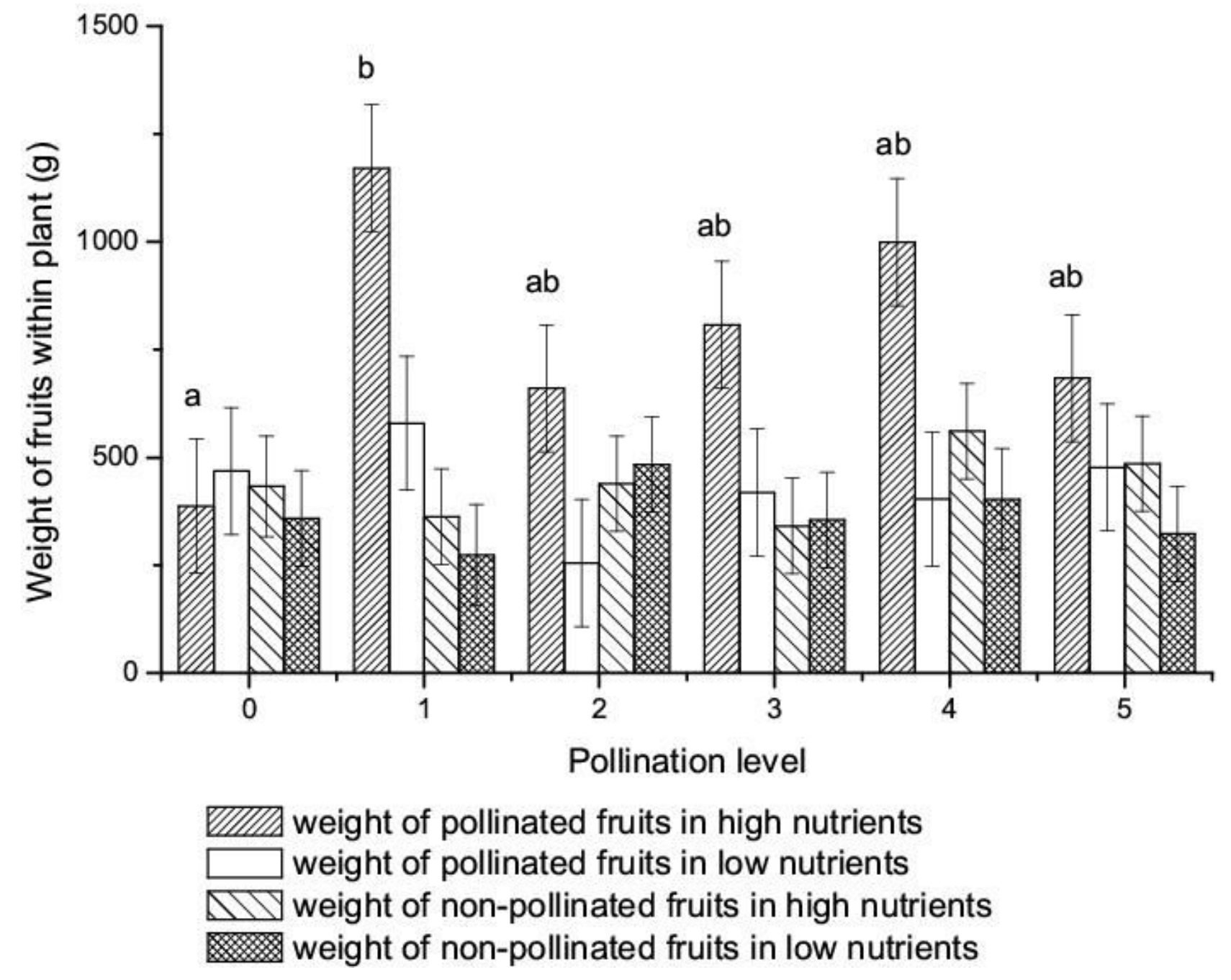

Figure 3

Weight of fruits per plant under different nutrient and pollination treatments. Plots show mean $\pm S E$, and different letters indicate significant differences, analyzed using two-way ANOVA with the Tukey test for multiple comparison testing. 


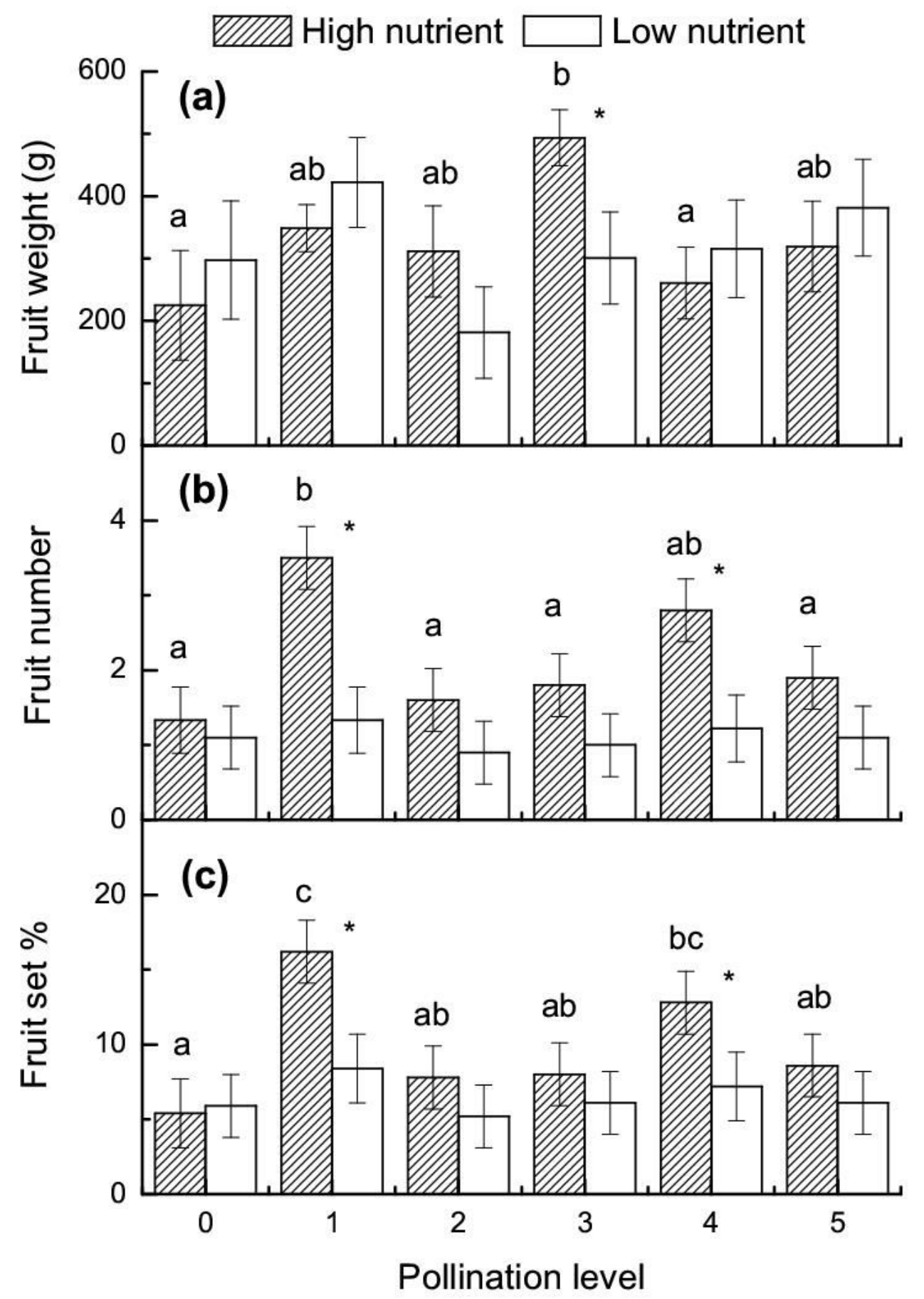

Figure 4

Fruit production (a: weight of fruit; $b$ : number of fruit; $c$ : fruit set) under different nutrient and pollination treatments. Plots show mean $\pm S E$, asterisks on the columns show significant differences between highand low-nutrient treatments, and different letters indicate significant differences, analyzed using two-way ANOVA with the Tukey test for multiple comparison testing. 


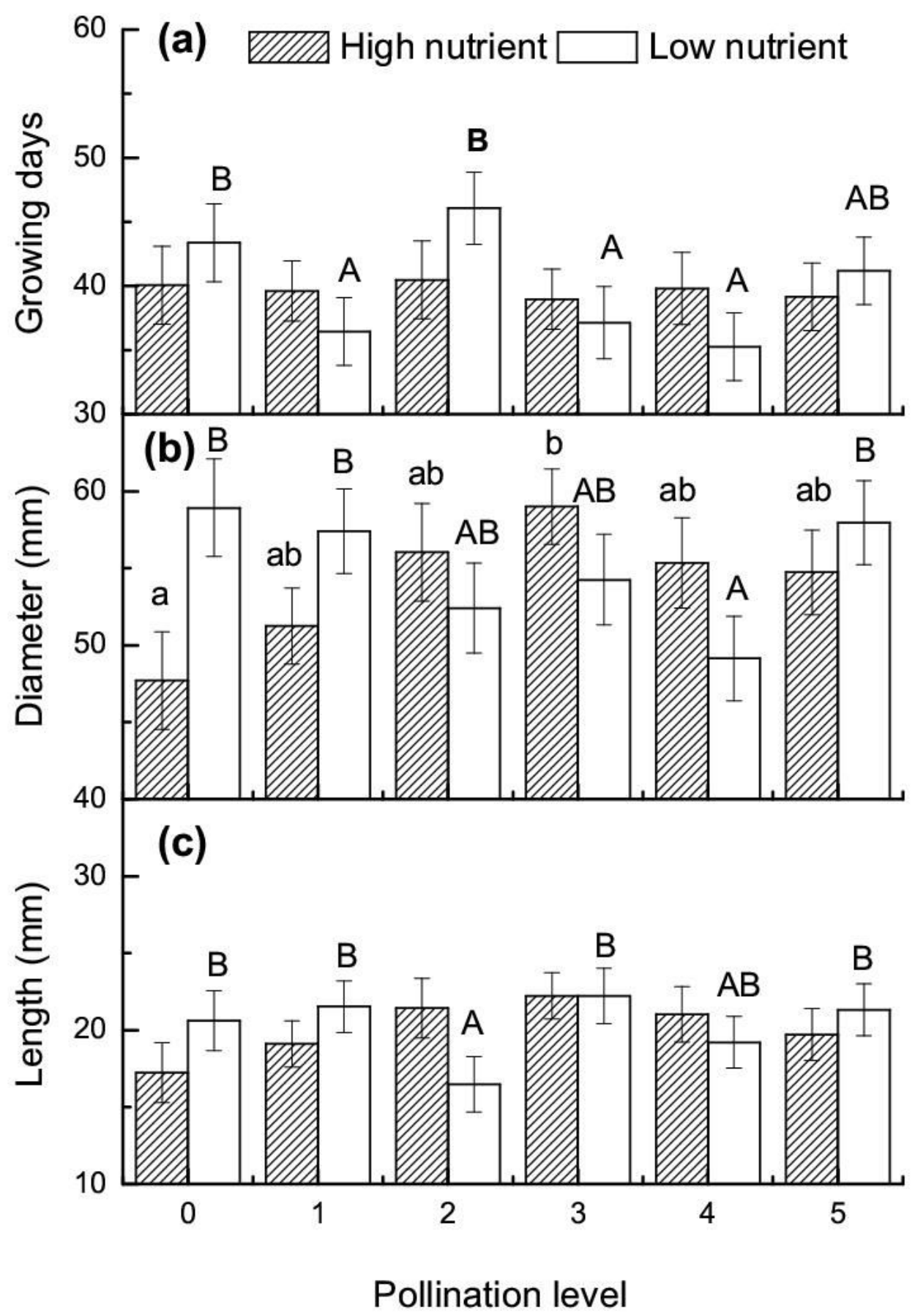

Figure 5

(a) Number of days required for fruit to reach maturity and (b) fruit diameter and (c) fruit length under different nutrient and pollination treatments. Plots show mean $\pm S E$, asterisks above the columns show significant differences between high- and low-nutrient treatments, and different letters indicate significant differences, analyzed using two-way ANOVA and the Tukey test for multiple comparison testing. 


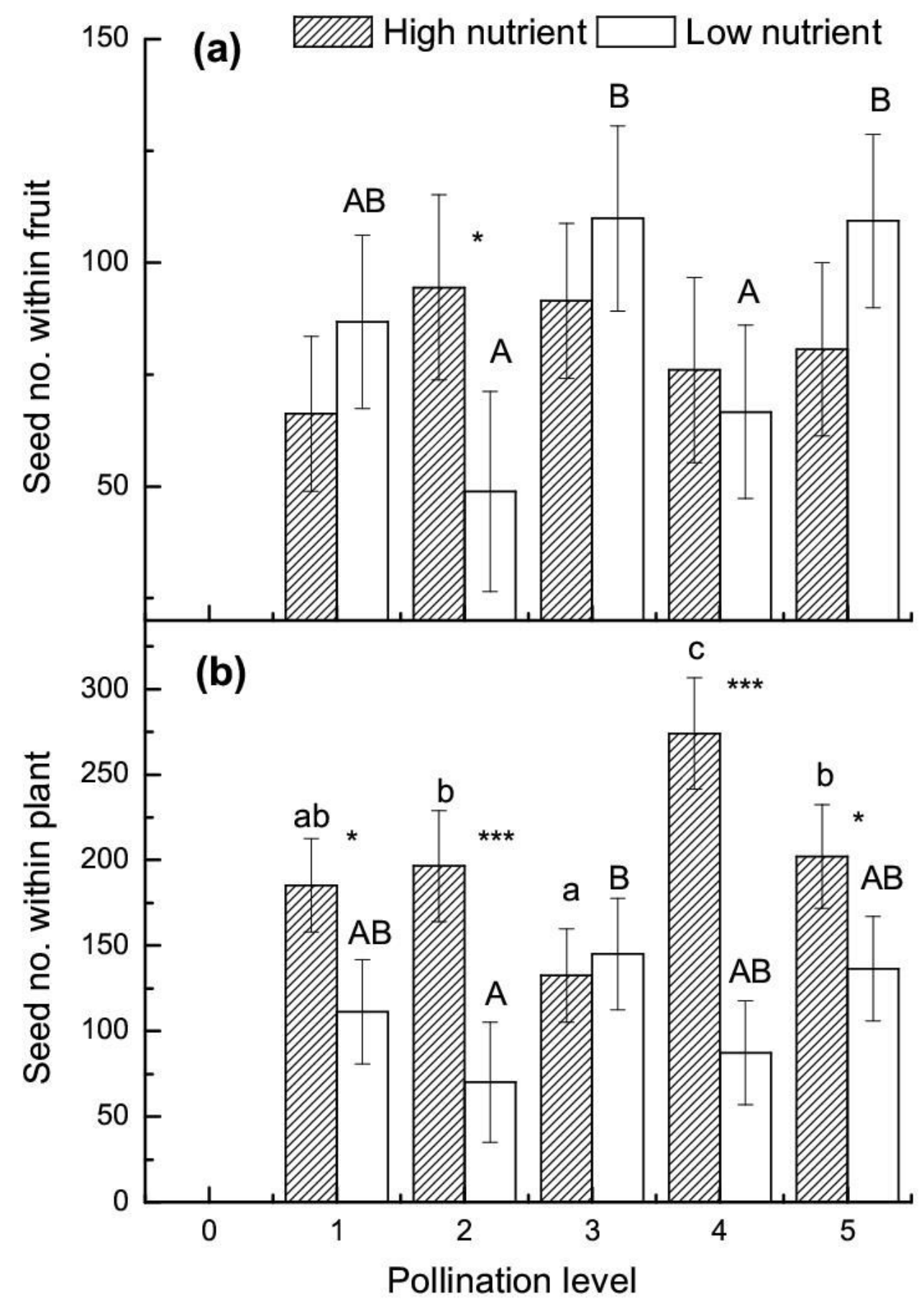

Figure 6

(a) Number of seeds per fruit and (b) total number of seeds per plant under different nutrient and pollination treatments. Plots show mean $\pm S E$, asterisks above the columns show significant differences between high- and low-nutrient treatments, and different letters indicate significant differences, analyzed using two-way ANOVA and the Tukey test for multiple comparison testing. 